\title{
INTERLEUKIN LEVELS IN PATIENTS WITH ESSENTIAL HYPERTENSION COMBINED WITH TYPE 2 DIABETES MELLITUS
}

\author{
Shelest B.O. \\ Kharkiv National Medical University, Ukraine
}

\begin{abstract}
The problem of combined course of hypertension of diabetes mellitus type 2 and obesity is becoming more common. This variant of comorbidity crucially increases the risk of cardiovascular complications. Inflammation is considered as an important link between the progression of hypertension and the development of adverse events. This study is devoted to the question of the relationship between the pro-inflammatory marker interleukin- 6 and the increased blood pressure in patients with concomitant diabetes and obesity. The treatment of such patients with combined pathology remains the actual and difficult issue of medical practice. The article analyses the dynamics of interleukin- 6 in the process of treatment with a fixed triple antihypertensive combination.
\end{abstract}

Key words: hypertension, interleukin-6, type 2 diabetes mellitus, obesity.

\section{Background}

Recent studies have confirmed the important role of inflammatory biomarkers in patients with arterial hypertension (AH). A constant increase in the number of articles on the role of immune disorders in the development of $\mathrm{AH}$ suggests crucial significance of this condition. Immune mechanisms involved in $\mathrm{AH}$ are recognized by many scientists, since initial changes in immune status are found in $85-87 \%$ of patients with $\mathrm{AH}$. Meanwhile, a number of scientists believe that immune processes are not decisive in the formation of initial manifestations of $\mathrm{AH}$, since patients with newly diagnosed disease and short disease history preserve immunity indices and sensitization of lymphocytes to the endothelium of the vessels increases only in chronical cases when complications reduce the number of immunocompetent cells and their activity.

Thus, a study of the cellular immunity state showed a change in the immune response presented by its inhibition according to the disease severity. Control of this process is carried out by

Corresponding Author:

Boris Shelest, $\mathrm{MD}, \mathrm{PhD}$, Associate professor of the Department of Internal and Occupational Diseases of Kharkiv National Medical University, Ukraine. E-mail: shelestb@ua.fm a wide range of immunocompetent cells and cytokines produced by them. The cytokines are involved in virtually every link of immunity and inflammation. However, their importance in the processes of damage, protection and repair of the endothelium remains poorly understood.

The issue of interleukin participation in $\mathrm{AH}$ combined with type 2 diabetes mellitus (DM2) secondary to obesity is of special interest nowadays. This combination is quite common and leads to a more significant increase in the incidence of cardiovascular events. The history of cytokines began in the middle of the twentieth century with the description of the effects of cachectin [1]. Later, many natural molecules were discovered and comprehensive description of their biological effects was made [2]. The term "interleukins" was proposed at the end of the 1970 s, but due to the wider impact of these substances on the human body exceeding the limits of the immune system, the term "cytokines" [2] has survived. Both terms are used today, due to its great influence. An important stage in the study of cytokines was observed in the 1980s, when murine and human interferon genes were cloned, recombinant molecules were created, fully replicating the biological properties of natural cytokines [3]. In the 1990s, after discovery of the subunit structure of cytokine receptors, the concept of "cytokine network" was formed and 
new cytokines were discovered by genetic analysis [1]. The general main properties of cytokines are pleiotropic effect, the absence of antigenic specificity, self-regulation of products and formation of cytokine network [3]. In this regard, cytokines can be isolated in an independent system of regulation of the functions of the body along with the nervous and hormonal ones. Within the immune system, they interact with nonspecific protective reactions and specific immunity, acting in both directions [2]. At the level of the body cytokines communicate with the immune, nervous, endocrine and other systems, including the regulation of protective reactions. Cytokines are the most universal regulatory system, since they realize their biological activity at the distant, after secretion by cell-producers, and in intercellular contact [4]. They affect virtually all cells involved in the development of inflammatory process, after being synthesized in the inflammation cell. There is a direct correlation with the content of IL- 6 and the level of arterial pressure in patients with $\mathrm{AH}$.

$\mathrm{AH}$ is usually associated with DM2 due to mutual pathogenesis promoted by inflammation. This kind of combination results in a higher risk of morbidity and mortality because of increased chances of cardiovascular events and renal disease [5]. A lot of studies evaluated changes in oxidative stress and inflammatory processes with time in hypertensive patients with DM2 [6,7]. The issue of impact exerted by inflammatory biomarkers on hypertension progression with and without presence of diabetes mellitus is not fully ascertained. Since AH is the most valuable among modifiable risk factor for cardiovascular complications of diabetes, a decrease in blood pressure is crucially important in improving the clinical outcomes [8]. And the problem of the treatment of patients with concomitant diseases including AH with DM2 with obesity is one of the most challenging problem of contemporary medicine.

\section{Purposes, subjects and methods:}

2.1 Purpose - to assess the efficacy of fixed combined antihypertensive therapy on IL-6 levels in patients with a combined course of $\mathrm{AH}$ and DM2.

\subsection{Subjects \& Methods}

The study involved 61 patients, including 29 men and 32 women aged 51 to $74(58.1 \pm 6.75)$ years (main group). The diagnosis of essential hypertension was made at systolic blood pressure (SBP) of $\geq 140 \mathrm{mmHg}$, and/or diastolic blood pressure (DBP) equal or over $90 \mathrm{mmHg}$ according to the criteria of the European (2013) and Ukrainian (2012) guidelines, all patients had stage 2 of AH, 11 patients (5 males, 6 females) had stage 1 of AH (SBP:140-160 $\mathrm{mm} \mathrm{Hg}$ ), and the rest (50 patients, 24 males, 26 females) had stage 2 of AH (SBP over $160 \mathrm{~mm} \mathrm{Hg}$ ). DM2 was established according to the IDF criteria (2015). The average HbAlc level was $7.73 \pm 1.19 \% .14 \%$ were smokers. The exclusion criteria were insulin dependent diabetes mellitus, valvular heart defects, connective tissue diseases, liver disease, cancer, remodeling of the heart and vessels, injuries, acute inflammatory process, chronic heart failure exceeding the second stage. The control group consisted of 30 age- and sex-matched persons with hypertension without the signs of DM2 and obesity. All the patients underwent ECG, EchoCG, ultrasound investigation of abdominal organs (by indications), radiography of the chest organs, clinical laboratory studies, basic biochemical blood plasma assay. Enzyme-linked immunosorbent assay was used for quantitative determination of IL-6.

All of the participants signed an informed consent and were entirely aware of the aims and methods of the study. The study was conducted according to the provisions of Helsinki Declaration of the World Medical Association and the statute of the Ukrainian Association of Bioethics and GCP regulations.

The antihypertensive therapy included a fixed combination of $4 \mathrm{mg}$ perindopril, $1.25 \mathrm{mg}$ indapamide and $5 \mathrm{mg}$ amlodipine. The control check-up of patients was carried out after 3 weeks and 6 months. Measurement of office blood pressure was carried out in the morning before administering medication after a 5-minute rest (three times with calculating the mean). The target office BP level was considered $<140 / 90$ $\mathrm{mm} \mathrm{Hg}$. The values are presented in the form of mean and standard deviations for quantitative values $(\mathrm{M} \pm \mathrm{m})$. Statistical analysis of the results was performed using Statistica 12.0 software. The differences were identified using t-test and Pearson correlation coefficient (PCC).

Conflict of interests. There is no conflict of interests.

\section{Results and discussion}

Clinical examination of the patients from the main group enrolled in the study at admission showed the following parameters: heart rate $81.9 \pm 4.51 \mathrm{bpm}$, left ventricular ejection fraction $53.9 \pm 5.34 \%$, total cholesterol: $6.11 \pm 1.55 \mathrm{mmol} / 1$, high-density lipoprotein cholesterol $0.89 \pm 0.09$ $\mathrm{mmol} / \mathrm{l}$, triglycerides $2.53 \pm 0.19 \mathrm{mmol} / 1$, plasma 
creatinine $63.7 \pm 3.43 \mathrm{micromol} / \mathrm{l}$, fasting glucose $5.1 \pm 0.3 \mathrm{mmol} / 1$.

Prior to treatment systolic blood pressure (SBP) was elevated by $21 \%$ and diastolic by $16 \%$ as compared to the control group. In 3 weeks of treatment by fixed combination (Chart 1), SBP decreased by $22.02 \%(168.1 \pm 10.3 \mathrm{mmHg}$ to $131.5 \pm 8.1 \mathrm{~mm} \mathrm{Hg}, \mathrm{p}<0.05)$, DBP by $16.33 \%$ ( $98.1 \pm 7.3 \mathrm{mmHg}$ to $82.5 \pm 5.1 \mathrm{mmHg}$ ). The target levels of blood pressure were identified in 41 (67\%) patients while $20(33 \%)$ patients did not reach them over the period of 3 weeks. In the group of AH combined with DM2, the content of interleukin-6 was $9.59 \pm 2.17 \mathrm{pg} / \mathrm{ml}$ (Chart 1). The level of IL-6 was over $8.0 \mathrm{pg} / \mathrm{ml}$ in all the main group patients.

Comparison of the initial IL-6 levels in patients with AH and DM2 and control group revealed its significant increase in the examined patients $(\mathrm{p}<0.01)$. The level of Il-6 decreased to $6.11 \pm$ $1.98 \mathrm{pg} / \mathrm{ml}$ (by $36.3 \%, \mathrm{p}<0.05$ ) 3 weeks after the fixed combination treatment, as presented in Chart 1. Assessment of correlation of blood pressure level with Il- 6 content in all the examined patients showed that the correlation coefficient

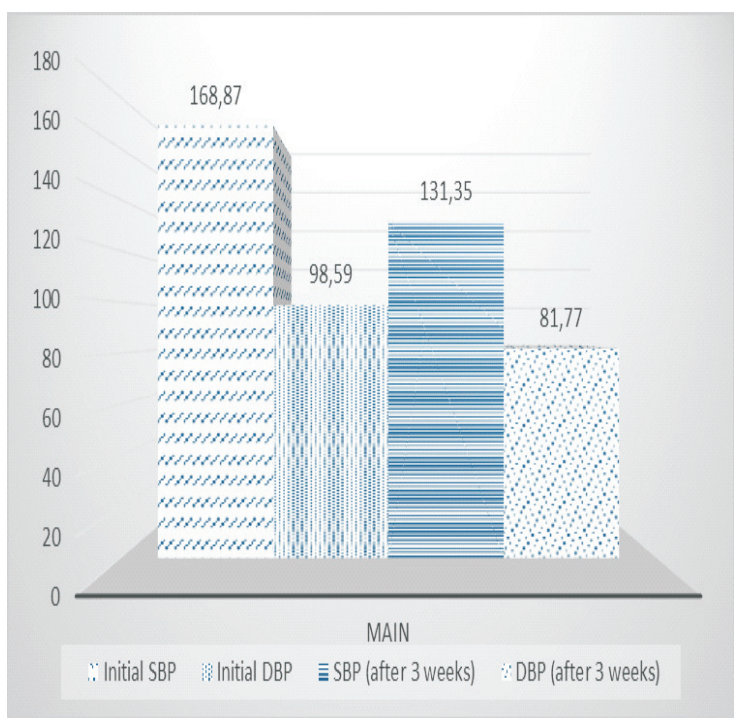

established the value of the correlation coefficient equal to $r=0.53(p<0.05)$, and $\triangle D B P: r=0.48$ $(\mathrm{p}<0.05)$. Another treatment regimen, including $8 \mathrm{mg}$ perindopril, $2.5 \mathrm{mg}$ indapamide and $5 \mathrm{mg}$ amlodipine was administered only to 2 patients after 3 weeks due to insignificant efficacy of the treatment.

Follow-up examination was performed 3 months after the start of treatment. SBP was $129.8 \pm 8.9 \mathrm{mmHg}$, which was $23.21 \%$ less than the initial level $(\mathrm{p}<0.01)$. DBP at that moment was equal to $79.3 \pm 8.1 \mathrm{mmHg}$, which was $19.4 \%$ less than the initial level $(\mathrm{p}<0.05)$. And all the patients were found to have the target levels of blood pressure. The results showed diminished level of Il-6, namely $4.57 \pm 1.42 \mathrm{pg} / \mathrm{ml}$, which was $52.63 \%$ less than before the treatment $(\mathrm{p}<0.05)$. The magnitude of correlation between the initial concentration of IL- 6 and ?SBP after 3 months was $r=0.55(p<0.05)$, ?DBP $-r=0.43(p<0.05)$.

A significant number of studies have been conducted to study the role of cytokines in the formation and nature of hypertension. It has been proved that interleukins, proteins responsible for intercellular communication produced by activated

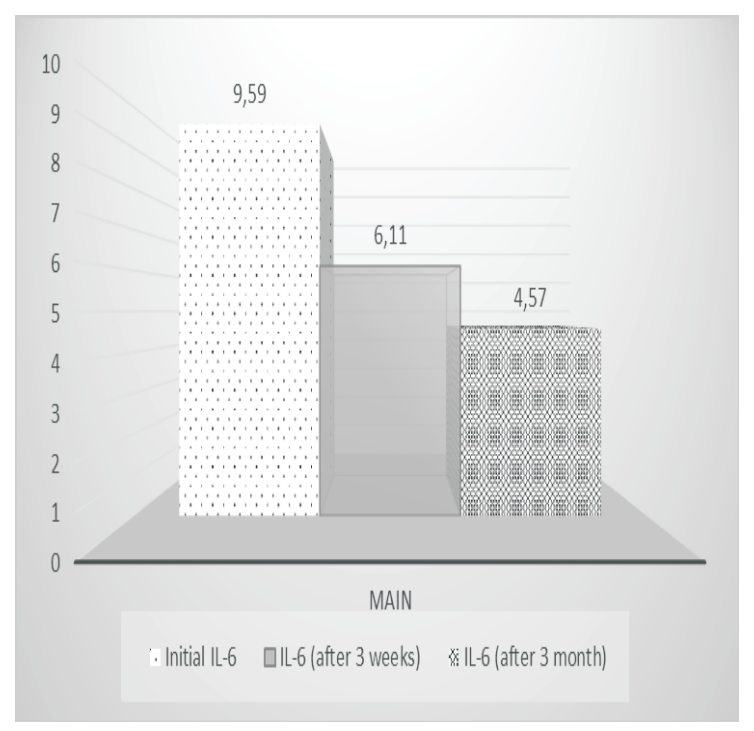

Chart 1. Interleukin-6 and blood pressure levels in the main and control groups and their changes with time secondary to treatment

between the level of SBP and Il- 6 concentration was $r=0.51(p<0.05)$, between the level of DBP and concentration of IL- $6 r=0.43(p<0.05)$. It is important to emphasize a significant decrease in blood pressure both with fast goal achievement evidences for high efficacy of suggested treatment scheme for patients with comorbid pathology.

Assessment of the relationship between the initial concentration of IL- 6 and ? SBP in 3 weeks after beginning of treatment in the main group immune cells, play an important role in the coordination of immunological responses in hypertension. The most typical effect is the induction of proliferation. With a wide range of biological properties, they represent a powerful communicative system that initiates and regulates inflammatory processes of all organs and systems [9]. Interleukins have their own serial numbers that do not belong to one subgroup of cytokines and they are united by the common functions. 
The name "interleukin" is given to the mediator in accordance with the criteria developed by the nomenclature review committee of the International Union of Immunological Societies: molecular cloning and expression of the gene of the studied factor; the presence of a unique nucleotide and an amino acid sequence; receiving neutralizing monoclonal antibodies; production by cells of the immune system, the presence of an important biologic function in the regulation of the immune response. Patients with AH combined with DM2 have impaired immune status, including changes in the cytokine profile of the body [10]. Much attention to interleukin 6 is due to the fact that this proinflammatory cytokine triggers the secretion of other cytokines and is one of the mediators of the acute phase of the process [11]. Increased coagulation and oxidative stress lead to the elevation of inflammatory cytokines such as interleukin-6, monocyte chemoattractant protein 1 , along with a decrease in insulin-like growth factor I in hypertensive patients with DM2. High IL-6 levels are linked with obesity and insulin resistance and have been manifested in various complications in DM2 patients [12].

It has been shown [13] that inflammation, along with oxidative stress, is a significant pathogenic chain in the progression of $\mathrm{AH}$ and DM2, especially with high blood pressure levels. Pouvreau C. et al. estimated that such inflammatory indices as interleukin-1 $\beta$ and interleukin-10 significantly differed from normotensive patients and patients with hypertension $(\mathrm{p}<0.03)$ and from the hypertensive compared to AH combined with DM2 patients $(\mathrm{p}<0.05)$. Assessing hypertension progression Pouvreau C. et al. also determined significant changes in the levels of inflammatory markers: insulin growth factor-1, monocyte chemoattractant protein 1 and $(\mathrm{p}<0.05)$. Thus, these patients with comorbidity require more intensive treatment regimen, especially in hypertensive patients with high blood pressure.

Investigation of Pouvreau C. et al. [13] showed that clinical combination of AH with DM2 and obesity requires special management of patients, which aims to reduce the increased risk of further morbidity and mortality. In addition, this study showed that patients with concomitant diabetes mellitus were treated by antihypertensive drugs much more intensively, which made it possible to significantly reduce both oxidative stress and the severity of inflammation, and it was similar to our study in the aspect of treating such patients. The significant difference between the control group and hypertensive patients with DM2 therefore indicates the potential use of these markers in clinical practice during examination of hypertensive patients with DM2.

Lukic et al. [14] revealed that obesity and type 2 diabetes mellitus (DM2) are associated with an increased risk of hypertension development, although the processes and chains contributing to hypertension in diabetes are not completely obvious. Lukic et al. analyzed the interdependence of insulin resistance (IR) levels, plasma insulin levels, and pro-inflammatory cytokines (IL- 6 and TNF- $\alpha$ ), which, were previously proven to be risk factors for hypertension in patients with type 2 diabetes who have increased body weight. Lukic et al. found that the IR index was significantly lower, and insulin levels were statistically elevated in the group of concomitant disorders: hypertension with DM2 and obesity. In addition, the group with concomitant disorders had statistically the highest IL-6 values, and the researchers found no significant difference in TNF- $\alpha$ levels. Our results correspond to the findings of Lukic et al. and the both studies ascertain that hypertension development depended on an increase in IR in patients with DM2 and obesity. This IR elevation was associated with an increase in the proinflammatory cytokine IL-6. The results of Lukic et al. suggest that interventions in reducing IR may be helpful in decreasing the risk of hypertension in patients with type 2 diabetes mellitus.

\section{Conclusions}

IL-6 concentration was significantly increased in patients with arterial hypertension and diabetes mellitus, compared with the control group. The level of IL-6 in patients with arterial hypertension and diabetes mellitus had a direct correlation connection with arterial pressure, to a greater extent with systolic and to a smaller one with diastolic. The treatment by fixed combination successfully decreased the IL-6 level in patients with combined arterial hypertension and diabetes mellitus unidirectional with a decrease in blood pressure. Moreover, the proposed therapeutic scheme allowed us to achieve target levels of blood pressure in 3-month period. Our study had some limitations, mainly due to a quite limited number of patients.

The further prospects are related to the deeper investigation of the nature of the relationship among the inflammatory indices in patients with various types of arterial hypertension comorbidity. 


\section{References}

1. Shtygasheva O.V., Ageeva E.S., Iptyshev V.M. (2011). Rol' immunoreguljatornyh citokinov v patogeneze hronicheskogo gastrita i jazvennoj bolezni, poisk prediktorov zabolevanij [The role of immunoregulatory cytokines in the pathogenesis of chronic gastritis and peptic ulcer disease, the search for predictors of diseases]. Sibirskij medicinskij zhurnal, 1, 88-90.

2. Ketlinskiy, S.A., Simbirtsev A.S. (2008). Citokiny. [Cytokines]. SPB: "Foliant", p. 408.

3. Galova E.A. (2008). Znachenie citokinov v patogeneze hronicheskogo gastroduodenita u detej doshkol'nogo vozrasta [Cytokines' significance in the pathogenesis of chronic gastroduodenitis in preschool children]. Citokiny i vospalenie. 7, (1), 48-51.

4. Zheleznjakova G.F. (2009). Citokiny kak prediktory techenija i ishoda infekcii [Cytokines as predictors of infection's course and outcomes]. Citokiny i vospalenie, 8, (1), 10-17.

5. Yan Q., Sun D., Li X., Chen G., Zheng Q., Li L., Gu C., Feng B. (2016). Association of blood glucose level and hypertension in Elderly Chinese Subjects: a community based study. BMC Endocr Disord, 16(1), 40.

6. Cheung B.M., Li C. (2012). Diabetes and hypertension: is there a common metabolic pathway? Curr Atheroscler Rep, 14(2), 160-6.

7. Al-Shukaili A., Al-Ghafri S., Al-Marhoobi S., Al-Abri S., Al-Lawati J., Al-Maskari M. (2013). Analysis of inflammatory mediators in type 2 diabetes patients. Int J Endocrinol, 2013, 976810.

8. de Boer I.H., Bangalore S., Benetos A. (2017) Diabetes and Hypertension: A Position Statement by the American Diabetes Association. Diabetes Care, 40, 1273.

9. Svetlova M.S., Vezikova N.N., Romashina V.V. (2009). Ocenka soderzhanija s-rb, interlejkina-1 i -6 i receptornogo antagonista interlejkina-1 v krovi bol'nyh rannim osteoartrozom kolennyh sustavov [Assessment of the C-RP, interleukin-1 and interleukin-6 and receptor antagonist interleukin-1 levels in patients with early osteoarthritis of the knee joints]. Terapevticheskij arhiv, 6, 52-56.

10. Godbout J.P., Glaser R. (2006). Stress-Induced Immune Dysregulation: Implications for wound Healing, Infections Disease and Cancer. J. Neuroimmune Pharmacol, 1, (4), 421-427.

11. Gadek-Michalska A., Bugajski A.J., Bugajski J. (2008). Prostaglandins and IL-1 $\beta$ in the hypothalamic-pituitary-adrenal response to systemic phenylephrine under basal. J. Physiol. Pharmacol, 59, (3), 563-575.

12. Butkowski E.G., Brix L.M., Al-Aubaidy H.A., Kiat H., Jelinek H.J. (2016). Diabetes, oxidative stress and cardiovascular risk. J Med Clin Sci, 5(1), 17-23.

13. Pouvreau C., Dayre A., Butkowski, E.G., de Jong B., Jelinek, H. F. (2018). Inflammation and oxidative stress markers in diabetes and hypertension. Journal of inflammation research, 11, 61-68.

14.Lukic L., Lalic N.M., Rajkovic N., Jotic A., Lalic K., Milicic T., Seferovic J. P., Macesic, M., Gajovic J. S. (2014). Hypertension in obese type 2 diabetes patients is associated with increases in insulin resistance and IL-6 cytokine levels: potential targets for an efficient preventive intervention. International journal of environmental research and public health, 11(4), 3586-98.

Received: $14-02-2019$

Accepted: 19-03-2019 